doi:10.7592/methis.v8i11.1007

\title{
Timotheus Vermeuleni ja Robin van den Akkeri metamodernism
}

Piret Viires

Timotheus Vermeuleni ja Robin van den Akkeri artikkel „Märkmeid metamodernismist" on omamoodi vastus Linda Hutcheoni üleskutsele otsida nime postmodernismijärgsele perioodile (Hutcheon 2002: 181). Metamodernism on üks mõistetest, mis on välja pakutud postmodernismile järgneva teoreetilise lähenemisena, nende hulgas altermodernsus, hüpermodernsus, automodernsus, digimodernism, neomodernism, performatism jm (vt ka Viires 2013). Samas leiavad Vermeulen ja van den Akker, et metamodernismi võiks näha ka laiema katusmõistena.

Mõiste metamodernism läks teaduslikku käibesse 2010. aastal, kui artikkel „Märkmeid metamodernismist" ilmus ajakirjas Journal of Aesthetics \& Culture (Vermeulen, van den Akker 2010). Autorid - hollandlased Timotheus Vermeulen ja Robin van den Akker - olid sel ajal doktorandid, Vermeulen õppis filmi ja televisiooni erialal Readingi Ülikoolis Inglismaal, van Akker filosoofiat Rotterdami Erasmuse Ülikoolis. Mõlema akadeemiline taust oli küllalt lai, näiteks oli Vermeulen kirjutanud inter- ja transmediaalsusest, esteetikast, filmist ja televisioonist, Jacques Rancière'ist. Van den Akkeri huvikese oli argielu ja linnaruum, samuti digitaalne kultuur, kaasaegne disain ja Henri Lefebvre. Selline lai kultuuriteoreetiline ja esteetiline taust andis hea aluse teha üldistusi post-postmodernse kultuurisituatsiooni kohta ja pakkuda omapoolseid lahendusi selle mõtestamiseks ja kirjeldamiseks. Praegugi on Robin van Akker tööl Rotterdami Erasmuse Ülikoolis ja tema uurimiskeskmeks on tänapäeva esteetika ja kultuur, argielu, sotsiaalne ruum ja aeg. Oma valmivas doktoritöös uurib ta, kuidas nutitelefonid mõjutavad meie käitumist avalikus ruumis ja muudavad meie linnakogemust.

Lühidalt kokku võttes väidavad Vermeulen ja van den Akker oma artiklis, et postmodernsuse aastad on möödas, nad vaatlevad hiljutisi arengusuundi arhitektuuris, kunstis ja filmis ning visandavad uue esilekerkiva tundestruktuuri piirjooned. Seda uut, modernse entusiasmi ja postmodernse iroonia vahel võnkuvat tundestruktuuri nimetavad nad metamodernismiks. Samas väidavad nad, et metamodernne väljendub kõige selgemini hiljutises uusromantilises pöördes.

Seega ei unusta nad täielikult ka postmodernismi, vaid väidavad, et "metamodernism peaks epistemoloogiliselt kuuluma (post)modernismiga kokku, olema ontoloogiliselt (post) modernismi vahel ja ajalooliselt teispool (post)modernismi“ (Vermeulen, van den Akker 2013: 130).

Võtmesõnaks metamodernismi mõistmisel ongi autorite jaoks metafoor metaksis, 'vahepealsus', mis tuleneb platonlikust mõistest metaxy. Nii iseloomustab metamodernismi pidev dünaamika ja kõikumine eri pooluste vahel. Seega on temas tubli annus postmodernismile omast ebamäärasust ja hämarapärasust. Samas hõlmab ta modernismile iseloomulikku selgust ja tõde. Autorid kirjeldavad seda dünaamikat järgmiselt: 
Ontoloogiliselt võngub metamodernism modernsuse ja postmodernsuse vahepeal. See võngub modernse entusiasmi ja postmodernse iroonia, lootuse ja melanhoolia, naiivsuse ja teadlikkuse, empaatia ja apaatia, ühtsuse ja paljususe, totaalsuse ja fragmenteerituse, selguse ja mitmetimõistetavuse vahepeal. Võnkudes niimoodi edasi-tagasi, peab metamodernism läbirääkimisi modernse ja postmodernse vahel. Sellest võnkumisest aga ei tohiks mõelda kui tasakaalust, pigem on tegu pendliga, mis võngub kahe, kolme, viie, kümne, lugematu arvu pooluste vahel. Iga kord, kui metamodernne entusiasm võngub fanatismi poole, tõmbab raskusjõud selle iroonia poole tagasi; hetkel, mil selle iroonia läheneb apaatiale, tõmbab gravitatsioon selle tagasi entusiasmi poole.

(Vermeulen, van den Akker 2013: 135-136.)

Vermeulen ja van den Akker leiavad, et uus, metamodernistlik diskursus esineb erinevates tänapäevastes kultuuripraktikates ja väjendub ennekõike selles, et uuesti on pöördutud transtsendentalismi, romantismi, lootuse, siiruse, afektiivsuse, narratiivsuse ja üleva suunas. Samas nad leiavad, et metamodernism tundub kõige selgemini väljenduvat esilekerkivas uusromantistlikus tunnetuses. Erinevate kirjanike, kunstnike, filmiloojate ja arhitektide reas, keda Vermeulen ja van den Akker metmodernistlike strateegiate kandjatena näevad, võiksid eesti Iugejale olla tuttavamad Wes Anderson, David Lynch, Haruki Murakami, Jonathan Franzen.

Kokkuvõtlikult iseloomustavad Vermeulen ja van den Akker metamodernismi mitte staatilisena, vaid pidevas liikumises olevana ning modernismi ja postmodernismi pingeväljas kõikujana:

Seega, kui modernne osutab ajalisele korrastatusele ja postmodernne ruumilisele korrastamatusele, siis metamodernset tuleks mõista kui aegruumi, mis on nii korrastatud kui ka korrastamata, aga samas ei kumbki. Metamodernism nihestab olevikku tulevikuta tulevikulise kohaloluga ning meie koha piire sürreaalse koha kohatusega. Niisugune on metamodernse mees/naise saatus: pürgida horisondi poole, mis alaliselt tagasi tõmbub. (Vermeulen, van den Akker 2013: 143.)

"Märkmeid metamodernismist" ei olnud üksik artikkel ja ühekordne projekt. Metamodernismi idee levitamiseks ja metamodernistlike teoste kaardistamiseks erinevatel kunstialadel Iõid Vermeulen ja van den Akker veebiajakirja Märkmeid Metamodernismist (Notes on Metamodernism). Metamodernism on esindatud ka Facebookis ja Twitteris. See tähendab, et metamodernismist huvitatute kogukond kasvab jõudsalt ja veebiajakirjas postitavad oma artikleid ja mõtteid üha rohkem uurijaid ja kriitikuid. Veebiajakiri on osa projektist, mille eesmärgiks ongi koguda kokku ja dokumenteerida arenguid esteetikas ja kultuuris, mille iseloomustamiseks ei ole kohane enam postmodernismi mõiste, vaid mida saaks määratleda pigem metamodernismi kaudu. Veebiajakirja postituste areaal on lai, hõlmates valdkondi nagu majandus, biopoliitika, võrgukultuur, arhitektuur, disain, mood, kunst, muusika, kirjandus, teater, performance, fotograafia, film, televisioon. Autoreid, kes selles veebajakirjas osalevad on praegu 25 , üle terve maailma ja erinevatelt aladelt. 
Eesti kriitikutest on metamodernismi seni põgusalt tutvustanud Piret Viires (Viires 2012) ja Maarja Kangro (Kangro 2011). Maarja Kangrole tundub, et miski hollandlaste elutundes loob kujutluse noorenenud Sisyphosest ja samas leiab, et metamodernismi strateegiate, s.t siiruseiroonia vahelise võnkumise, performatismi, romantilise kontseptualismi abil annab hästi tõlgendada Urmas Vadi loomingut (Kangro 2011: 135-136). Metamodernismist on kirjutanud ka Kairi Prints (Prints 2011) ja teatriga seostuvalt Kristiina Reidolf (Reidolf 2011). Põhjalikku ja järjekindlat metamodernismi rakendust eesti kultuuriuurimuses pole veel olnud, võimalik, et praegune artikli „Märkmeid metamodernismist“ avaldamine Methises võib seda ergutada.

Seda, kas metamodernismi mõiste läheb laiemalt käibele ja jääb domineerivaks kontseptsiooniks postmodernismijärgse kultuurisituatsiooni kirjeldamiseks, võime ainult oletada. Üks eelis metamodernismil kahtlemata on - kuna Veremeuleni ja van den Akkeri võtmeartikkel on veebis vabalt kättesaadav ja seda toetab pidevalt täienev veebiajakiri, siis leiavad selle tõenäoliselt üles kõik uurijad, kes otsivad vastust küsimusele, mis on saanud pärast postmodernismi.

Igatahes on Timotheus Vermeulen ja Robin van den Akker võtnud tõsiselt Linda Hutcheoni üleskutset leida nimi post-postmodernismile ja pakkunud välja omapoolse lahenduse. Nüüd sõltub juba lugejatest, kriitikutest ja meist kõigist, kas metamodernism osutub kontseptsiooniks, mis on tulnud selleks, et jääda.

\section{Kirja nd us}

Hutcheon, Linda 2002. The Politics of Postmodernism. 2nd edition. London, New York: Routledge. Kangro, Maarja 2011. Kelle laipa ja millist retoorikat otsitakse? - Vikerkaar, nr 4-5, Ik 133-137.

Prints, Kairi 2011. Metanaer uussiiruse üle. - Eesti Ekspress, Areen, 2. juuni.

Reidolf, Kristiina 2011. Milline on elu pärast postmodernismi? - Sirp, 29. juuli.

Vermeulen, Timotheus, Robin van den Akker 2010. Notes on Metamodernism. - Journal of Aesthetics \& Culture. (Online) Vol. 2. - http://aestheticsandculture.net/index.php/jac/article/viewArticle/5677 (10.05.2013).

Vermeulen, Timotheus, Robin van den Akker 2013. Märkmeid metamodernismist. - Methis. Studia humaniora Estonica, nr 11, Ik 130-145, doi:10.7592/methis.v8i11.1007

Viires, Piret 2012. Postmodernism in Estonian Literary Culture: Frankfurt am Main, Berlin, Bern, Bruxelles, New York, Oxford, Wien: Peter Lang Verlag.

Viires, Piret 2013. Digimodernistlik eesti kirjanik. - Methis. Studia humaniora Estonica, nr 11, Ik 9-21, doi:10.7592/methis.v8i11.999

\section{Ve e bi a I I i k a d}

Notes on Metamodernism - http://www.metamodernism.com (30.05.2013). 